\title{
THE BLOOD PHOSPHORUS IN EGYPTIAN INFANTS
}

\author{
BY \\ I. A. SABRI, M.R.C.P., D.T.M.\&H. \\ and M. A. ABBOUD, M.R.C.P., D.C.H. \\ (From the Paediatric Department, Faculty of Medicine, Cairo)
}

\begin{abstract}
Rickets is not a new disease to Egypt. Its existence dates back to ancient times. Drawings in old Egyptian tombs show that rickets existed in the times of the Pharaohs (Ruffer, 1921). Until recently (Dicks, 1922) the disease was considered to be rare in Egypt. Shawki (1928), however, demonstrated that rickets is prevalent in this country. Nearly 50 per cent. of all Egyptian infants between the ages of six months and two years suffer from this malady. Statistics collected later by Sabri (1933a) showed that even in Upper Egypt, where sunshine is abundant, rickets is nearly as common as in Cairo. The possible factors concerned in the prevalence of this disease among Egyptian infants have been the subject of many recent investigations.
\end{abstract}

Milk, the basic diet of every infant, was first investigated. It was shown (Sabri and Fikri, 1932) that human, cow's and buffalo's milks (the milks commonly used for infant-feeding in Egypt) do not contain active vitamin D in any amount that can be of practical value in the prevention of rickets. On the other hand, these milks contain sufficient amounts of the precursor of vitamin $\mathrm{D}$ (provitamin $\mathrm{D}$ ), which after activation by exposure to ultra-violet rays endows these milks with definite antirachitic powers. Thus, the Egyptian infant, whether naturally or artificially fed, receives most of the antirachitic factor in its milk-supply in an inactive form. Unless this factor is activated by exposure of the child to ultra-violet irradiation-obtained from natural or artificial sources-no protection against rickets is provided. There cannot be any question of lack of sunshine in this country even in the midst of the winter months. The daily average hours of sunshine during the winter season is about eight hours. Yet, in spite of these long hours of sunshine, a great part of vitamin $D$ in human and animal milks remains in an inactive form (provitamin D). These facts point to an insufficient supply of ultra-violet rays. Over-clothing, bad housing and other more or less minor factors undoubtedly play a part, but they cannot be mainly responsible for the prevalence of the disease all over the country. An insufficient content of ultra-violet rays in Egyptian sunshine appeared to us (Sabri, 1933b) to be the only explanation. Shawki (1928) came to similar conclusions in 1928. Estimations of the effective 
ultra-violet rays worked out in 1932 (Hill's method) showed that in spite of an abundant supply of sunshine the quantity of ultra-violet rays is much below the expected. This is especially marked in the winter and spring seasons, and is ascribed to certain physical and meteorological factors (fig. 1).

\section{Present investigations}

Because of the pronounced effect of ultra-violet rays on the inorganic blood phosphorus, it was thought that a curve showing the seasonal variation of blood phosphorus in healthy Egyptian infants might further help to elucidate the etiology of rickets. Infants of an average age of six months from the Child

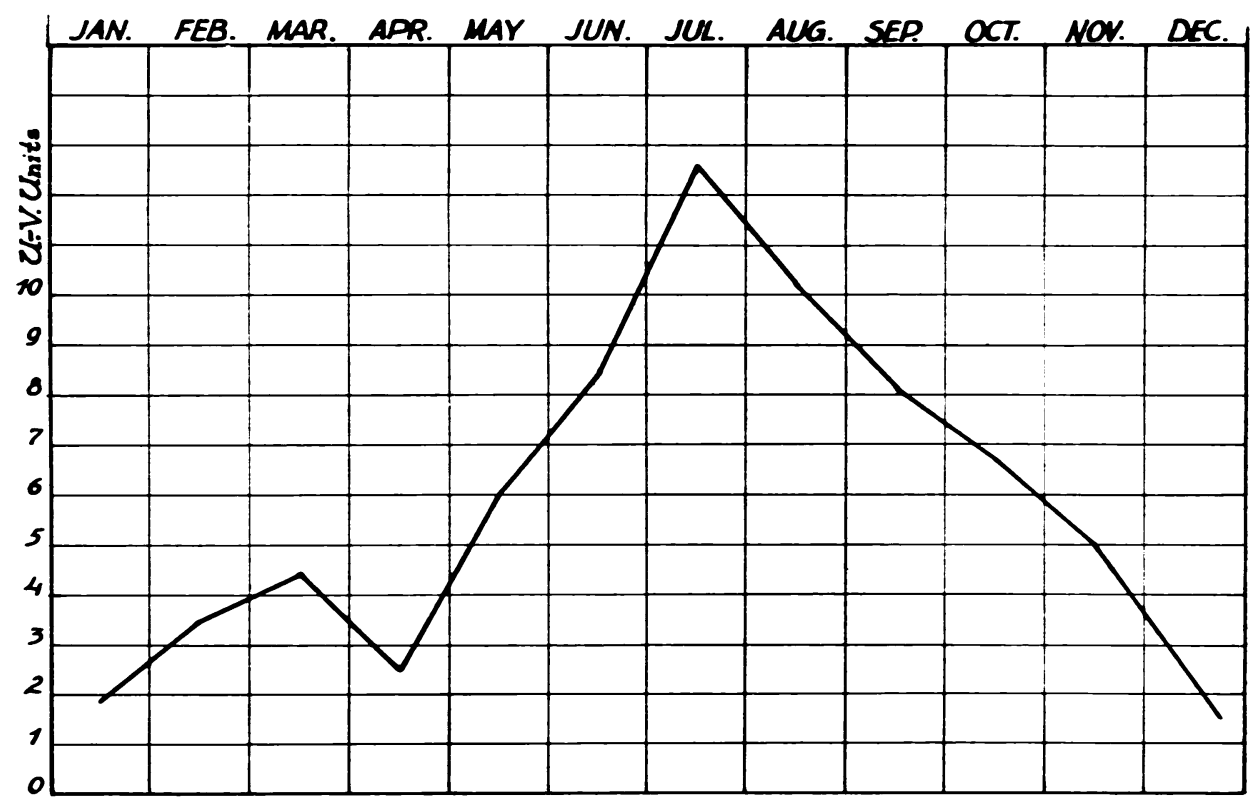

Graps of Ultraviolet Rays in Cairo (after Orara)

Fig. 1.

Welfare Centre and the Foundling Home of Fouad I Children's Hospital, Cairo, were investigated. Only those free from any rachitic manifestations (clinically and radiologically) were selected. The investigations were continued over a period of one year (May, 1935, to April, 1936). During this time the infants were not given any special antirachitic therapy. Blood-phosphorus estimations and skiagrams were made monthly. Those children who developed rickets or any other severe nutritional disturbance during the course of investigation were excluded.

Of two hundred infants who were investigated, only eighty-three continued to be healthy and non-rachitic. The composite blood-phosphorus curve of those infants is shown in fig. 2. The examination of this graph demonstrates two important points : 
(1) There is a close relationship between the ultra-violet content of sunshine and blood-phosphorus curves of infants.

(2) During a great part of the year the blood-phosphorus level of healthy non-rachitic infants reaches a dangerously low level $-4 \cdot 1$ to $4 \cdot 3 \mathrm{mgm}$. per cent.

\section{Comments}

The influence of ultra-violet rays on the inorganic blood phosphorus is already established. It is known that the rise and fall in blood phosphorus

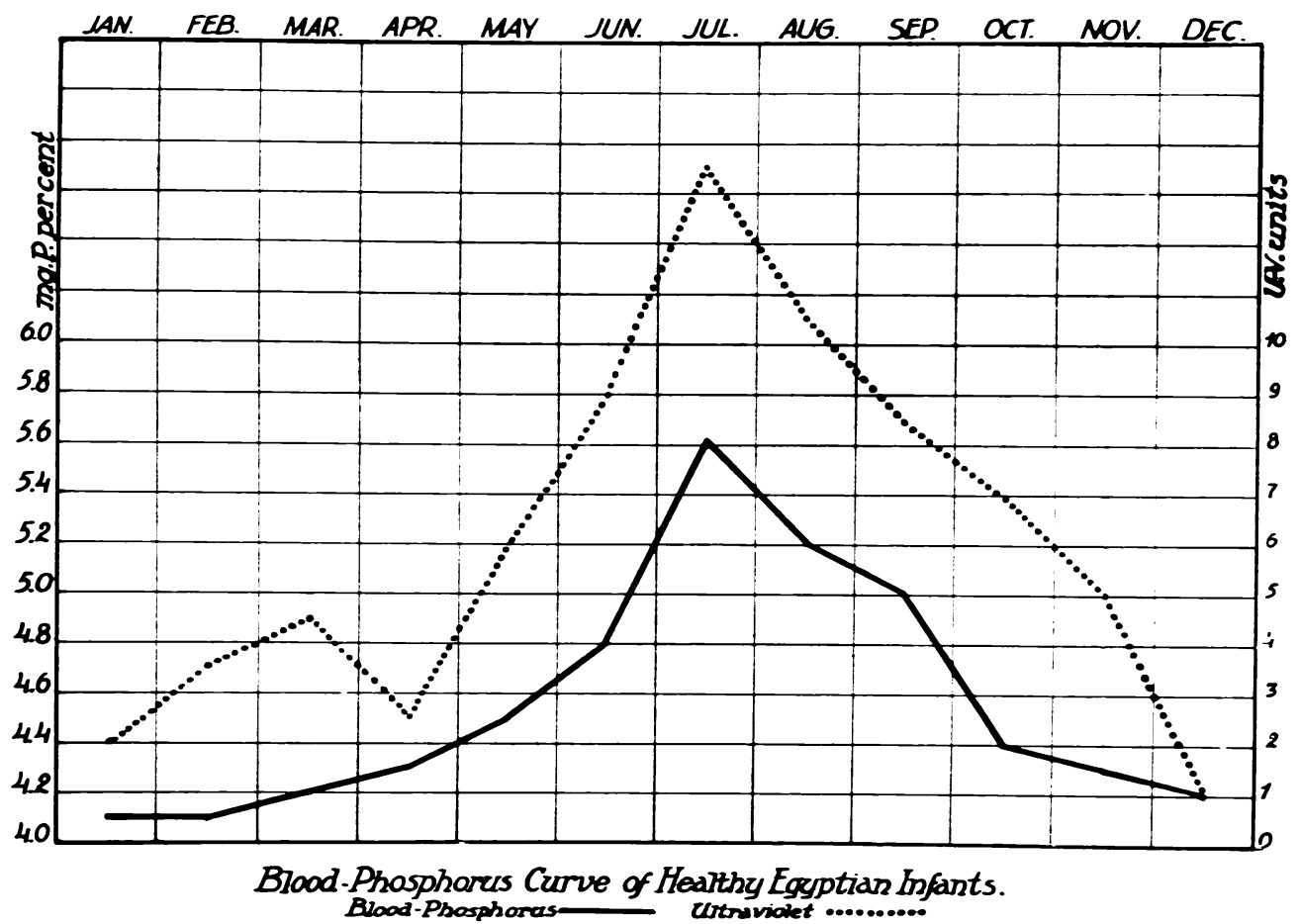

Fig. 2.

follows increase and decrease in the amount of ultra-violet rays in sunshine (Hess, 1930). This close relationship between blood-phosphorus level and ultra-violet rays is well illustrated in the present curve. The changes in the inorganic blood phosphorus which take place in rickets have already been worked out by Kramer (1933) and others, who showed that in the healthy infant, blood phosphorus lies between 4.5 and $5.5 \mathrm{mgm}$. per cent. In infantile rickets the inorganic phosphorus is reduced, and usually lies between 2 and $4 \mathrm{mgm}$. per cent. Four mgm. per cent. represents the usual dividing-point between the rachitic and normal conditions.

It will be noted from the graph that the blood phosphorus of healthy Egyptian infants falls during the winter and spring seasons to a low level- 
$4 \cdot 1$ to $4 \cdot 3 \mathrm{mgm}$. per cent. ; in other words, it almost lies on the border-line between normal and rachitic conditions.

Thus, the Egyptian infant is naturally predisposed, during a great part of the year, to develop rickets. The presence of some additional factor, such as defective housing, overclothing or seclusion of the child, is sufficient to turn the balance unfavourably. It is no wonder, therefore, that rickets is so prevalent among Egyptian children.

Thanks are due to Dr. S. Naga, radiologist of Fouad I Children's Hospital, for his great help and assistance.

\section{REFERENCES}

Dick, L. (1922). Rickets, London.

Hess, A. F. (1930). Rickets and Osteomalacia, London, 111.

Kramer, B. (1933) in Parsons and Barling, Diseases of Infancy and Childhood, London, 243.

Omar, W. (1932). J. Egypt med. Ass., 15, 12.

Ruffer, M. A. (1921). Studies in the Palaeo-pathology of Egypt, Chicago.

Sabri, I. A., and Fikri, M. M. (1932). Arch. Dis. Childh., 7, 41.

- (1933a). Report to the Egyptian University on the Incidence of Rickets in Egypt. (1933b). Trans. Third internat. Paed. Cong., Uppsala, 442.

Shawki, I. (1928). Rep. internat. Cong. trop. Med. Hyg., Cairo, 2, 691. 